\title{
Low-frequency ultrasound induces apoptosis of rat aortic smooth muscle cells (A7r5) via the intrinsic apoptotic pathway
}

\author{
B. Zhang ${ }^{1}$, H.S. Zhou ${ }^{2}$, Q. Cheng ${ }^{3}$, L. Lei ${ }^{1}$ and B. Hu ${ }^{4}$ \\ ${ }^{1}$ Department of Echocardiography, East Hospital, \\ Tongji University School of Medicine, Shanghai, China \\ ${ }^{2}$ Shanghai Acoustics Laboratory, Chinese Academy of Sciences, \\ Shanghai, China \\ ${ }^{3}$ Institute of Acoustics, Tongji University, Shanghai, China \\ ${ }^{4}$ Department of Ultrasound in Medicine, \\ Shanghai Institute of Ultrasound in Medicine, \\ Shanghai Jiao Tong University Affiliated Sixth People's Hospital, \\ Shanghai, China \\ Corresponding author: $\mathrm{B}$. $\mathrm{Hu}$ \\ E-mail: binghubo@yahoo.com.cn
}

Genet. Mol. Res. 13 (2): 3143-3153 (2014)

Received March 27, 2013

Accepted September 3, 2013

Published April 17, 2014

DOI http://dx.doi.org/10.4238/2014.April.17.10

\begin{abstract}
Ultrasound, a non-invasive therapy method, is a potential tool for medical applications, but its biological effects on vascular smooth muscle cells (VSMCs) have not been characterized. The aim of this study was to explore the effect and possible apoptotic mechanism of VSMCs that were induced by low-frequency ultrasound (LFU). Cell viability and apoptosis of A $7 \mathrm{r} 5$ cells were evaluated after treating A7r5 cells with a continuous $45-\mathrm{kHz} 1.0-\mathrm{W} / \mathrm{cm}^{2}$ ultrasound (exposure time of $0,10,20,30$, and $35 \mathrm{~s}$ ) by MTT assay and flow cytometry. At the optimum ultrasound exposure condition (30 s), gene chip analysis was performed, and the apoptotic signaling pathway was confirmed by reverse transcription-polymerase chain reaction and Western blot.
\end{abstract}


As measured by flow cytometry, LFU significantly induced A7r5 cell apoptosis. Comparing the ultrasound group with the control group, the protein expression of caspase- 9 and caspase- 3 was increased by 50 and $57 \%$, respectively; the caspase- 3 mRNA level was increased by $37.5 \%$. These findings indicate that an intrinsic pathway plays a major role in apoptosis that is induced by LFU and that LFU can induce A7r5 cell apoptosis via caspase-9- and caspase-3-dependent pathways.

Key words: A7r5 cells; Apoptosis; Caspase-9; Caspase-3; Low-frequency ultrasound

\section{INTRODUCTION}

Vascular smooth muscle cells (VSMCs) are essential for good performance of the vasculature. By contracting and relaxing, VSMCs play an important role in maintaining an appropriate blood pressure by altering the luminal diameter, and they also perform other functions, which become progressively more important during vascular remodeling (Owens et al., 2004; Hayashi and Naiki, 2009). Unlike other muscle cells, VSMCs do not terminally differentiate. They can shift reversibly along a continuum from a contractile phenotype (also known as differentiated phenotype or quiescent phenotype) to a synthetic phenotype (also known as dedifferentiated phenotype or activated phenotype) (Beamish et al., 2010). In this process, the increased proliferation and migration of VSMCs are undoubtedly required and potent for vascular repair (Beamish et al., 2010). However, the excessive proliferation of VSMCs can aggravate vascular injury, which was reported to occur in restenosis after angioplasty (Reimers et al., 1997). Therefore, it is important to find strategies to prevent the excessive proliferation or induce the apoptosis of VSMCs to a certain extent that does not compromise the normal cellular expansion.

Ultrasound, a kind of non-ionizing energy, has been used in various therapeutic medical applications, including sonophoresis (ultrasonic transdermal drug delivery), dentistry, eye surgery, body contouring, breaking kidney stones, eliminating blood clots, and increasing bloodbrain barrier permeability (Ahmadi et al., 2012; Man et al., 2012; Xia et al., 2012). Several reports have demonstrated that ultrasound can induce cell apoptosis (Fang et al., 2007; Hundt et al., 2007; Chida et al., 2009; Tsuang et al., 2011). Recently, low-frequency ultrasound (10-60 $\mathrm{kHz}$ ) has received increased attention as a rapid and reagent-less method because of its use to enhance various biotechnological processes as a non-invasive therapy method (Rokhina et al., 2009), while the mechanism has not been fully characterized. Lower frequency acoustic waves have greater tissue penetration than higher frequency acoustic waves because of their longer wavelength (Man et al., 2012); thus, low-frequency ultrasound can easily penetrate deep tissue. Some studies have shown that low-frequency ultrasound irradiation has an antitumor ability by inhibiting tumor cell proliferation and inducing apoptosis (Lejbkowicz and Salzberg, 1997; Jiang et al., 2012), and the antitumor effect is enhanced by combining the treatment with antitumor drugs, such as hematoporphyrin, adriamycin, endothelial monocyte-activating polypeptide II, and quercetin (Paliwal et al., 2005; Meng et al., 2008; Zhang et al., 2010).

Considering the potency of low-frequency ultrasound on the proliferation and apoptosis of cells, we speculate that low-frequency ultrasound may have a similar effect. However, to date, there are few studies about the effect of ultrasound on the proliferation and apoptosis of VSMCs, and the role of the apoptotic pathway remains unclear. 
In order to investigate the effect of low-frequency ultrasonic treatment on aortic smooth muscular cells (A7r5 cells) and apoptosis, this study was performed with a continuous $45-\mathrm{kHz} 1.0-\mathrm{W} / \mathrm{cm}^{2}$ ultrasound. The results showed the effect of ultrasound on the apoptosis of VSMCs, and they indicated that caspase-3- and caspase-9-dependent pathways play key roles in apoptosis that was induced by ultrasound, which may potentially be considered as a new therapeutic tool for restenosis after angioplasty.

\section{MATERIAL AND METHODS}

\section{Cell preparation}

A7r5 cells (VSMCs) were purchased from the cell bank of Chinese Academy of Science and were cultured on 100 x 20-mm tissue culture dishes (Falcon, Oxanard, CA, USA) in Dulbecco's modified Eagle's medium (DMEM) supplemented with $5 \%$ fetal calf serum and $5 \%$ newborn calf serum, $2 \mathrm{M} \mathrm{L}$-glutamine, $100 \mathrm{U} / \mathrm{mL}$ penicillin, and $100 \mathrm{mg} / \mathrm{mL}$ streptomycin (Hyclone, Logan, UT, USA) at $37^{\circ} \mathrm{C}$ in a humidified atmosphere of $5 \% \mathrm{CO}_{2}$ and $95 \%$ air. The cells were harvested, resuspended, and immediately used for the experiment at a concentration of $10^{6}$ cells $/ \mathrm{mL}$ at $80 \%$ confluence in $2-\mathrm{mL}$ tubes. The cells were subcultured twice per week, and cell numbers were counted by the use of a hemocytometer (Anxin Optical Equipment, Shanghai, China). The viability of the cells was determined by the trypan blue exclusion test. In all cases, cell viability was greater than $90 \%$. Cultures were passaged upon reaching confluence by brief exposure to phosphate-buffered saline (PBS) containing $0.5 \mathrm{mg} / \mathrm{mL}$ trypsin and $0.5 \mathrm{mM}$ EDTA at $37^{\circ} \mathrm{C}$, and they were subcultured in DMEM supplemented with serum and antibiotics as described above. Cell growth was observed under an inverted phase contrast microscope (Carl Zeiss, Oberkochen, Germany).

\section{Ultrasound apparatus}

The ultrasound apparatus (model: DM-40 Shanghai Acoustics Laboratory, Chinese Academy of Sciences) was used. The experimental apparatus mainly consisted of 2 parts: an ultrasonic generator and a transducer. The ultrasonic transducer units, operating at a frequency of $45 \mathrm{kHz}$ (effective radiating area, $38.04 \mathrm{~cm}^{2}$ ), were positioned sidewise in the bottom of a water bath. The transducer was connected to an ultrasonic generator, which worked in a continuously adjustable frequency, and its maximum output electric power was about 50 W. In addition, the output electric power was monitored by a digital electric power analyzer (model: PPA2500; N4L). By adjusting the electric power, the ultrasound intensity was set. A needle-type hydrophone (model: SPRH-S-1000; SEA), which was positioned in the tube and connected to a digital oscilloscope (model: TDS 1024B; Tektronix), was used to check the operating conditions.

\section{Protocol for ultrasound treatment}

A $7 \mathrm{r} 5$ cells of confluent cultures were trypsinized and were suspended at a concentration of $5 \times 10^{5}$ cells $/ \mathrm{mL}$ DMEM in a culture tube measuring $16 \times 125 \mathrm{~mm}$ (Corning, Staffordshire, UK). The tubes were then positioned in the tube holder so that the cell suspension was 
in the middle of the transducer at a distance of $10 \mathrm{~mm}$ from its surface within the "near field" of the ultrasound beam (Figure 1). Then, they were exposed to ultrasound irradiation using the ultrasound apparatus described above. The frequency of the ultrasound was $45 \mathrm{kHz}$. The ultrasound intensity of $1.0 \mathrm{~W} / \mathrm{cm}^{2}$ was achieved by adjusting the electric power. The exposure time to ultrasound was set at $0,10,20,30$, and $35 \mathrm{~s}$ for each tube of cells. To avoid the thermal effect of ultrasound, the culture tube was put in a thermostatic water bath (precision: $\pm 0.05^{\circ} \mathrm{C}$ ), and the temperature was measured by thermocouple in the test tube and the bath. To diminish the effect of standing waves, the tube was shaken slightly during ultrasound irradiation.

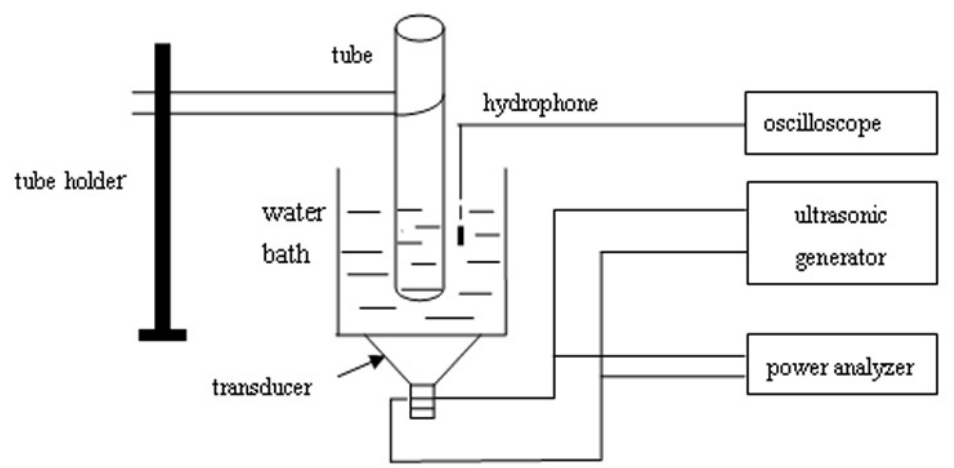

Figure 1. Schematic diagram of sonication set-up.

\section{Viability of ultrasound-treated cells by tetrazolium (MTT) assay}

In the MTT assay, aliquots of A7r5 cells (at 10,000 cells per well) were trypsinized, suspended, treated by ultrasound, and transferred to a fibronectin $\left(25 \mathrm{ng} / \mathrm{mm}^{2}\right)$ precoated flatbottomed 96 -microwell plate $(0.1 \mathrm{~mL} /$ well $)$. Briefly, the MTT assay was performed according to the manufacturer recommendation. The absorption was determined at $492 \mathrm{~nm}$ using the microplate reader (Kontron SLT-210-Thermo Fisher Scientific, Waltham, MA, USA). Tetrazolium dissolved in dimethyl sulfoxide and diluted in PBS to a final concentration of $7 \mathrm{mM}$ was added (10 mL MTT/well) to each well. After incubation for 4 h, $100 \mathrm{~mL} 0.004 \mathrm{~N} \mathrm{HCl}$-isopropanol was added to each well, and the contents were vigorously mixed by repeated pipetting. After $5 \mathrm{~min}$, the plates were read by an enzyme-linked immunosorbent assay reader (Kontron SLT-210) at a wavelength of $492 \mathrm{~nm}$, and the results are reported as optical density (OD).

\section{Detection of apoptotic cells by flow cytometry}

To observe cells undergoing apoptosis, the cells were stained with fluorescein isothiocyanate (FITC)-conjugated annexin V and propidium iodide (PI) using the Annexin V-FITC Apoptosis Detection kit according to the manufacturer recommendation (KeyGEN, Nanjing, China). Briefly, the cells were harvested and washed twice with PBS, resuspended in $500 \mu \mathrm{L}$ binding buffer, and incubated with $5 \mu \mathrm{L}$ annexin $\mathrm{V}$ and $5 \mu \mathrm{L}$ PI for $15 \mathrm{~min}$ in the dark at room temperature. Then, $1 \times 10^{4}$ cells were measured with a flow cytometer using the Cell Quest software. The percentage of apoptotic cells was determined using a flow cytometer (BD FACSCalibur; Becton, Dickinson and Company, Franklin Lakes, NJ, USA). 


\section{Gene display analysis}

To determine the effect of ultrasound on the gene expression in A $7 \mathrm{r} 5$ cells, the supernatants from control and ultrasound-treated ( $30 \mathrm{~s})$ cells were collected. Invitrogen Trizol was used to extract total RNA according to manufacturer instructions. Reverse transcription, cDNA synthesis, and biotinylated cDNA were prepared from 100 ng total RNA according to the standard RocheNimbleGen protocol. Briefly, $5.5 \mu \mathrm{g}$ cDNA was hybridized for $16 \mathrm{~h}$ at $45^{\circ} \mathrm{C}$ on GeneChip Human Gene 1.0ST Array. GeneChips were washed and stained in the Affymetrix Fluidics Station 450 and were scanned using the GeneChip Scanner 3000 7G. The data were analyzed with Partek Genomics Suite version 6.5 using Robust Multichip Analysis settings and global scaling as the normalization method. Then, the Significance Analysis of Microarrays software was used for data analysis (Tusher et al., 2001). Usually, the selection standard of gene difference is to control the false-discovery rate to less than $5 \%$ and the fold-change is over 1.5 or 2 .

\section{Detection of caspase- 3 and caspase- 9 expression in A7r5 cells}

Real-time quantitative PCR was used to detect apoptotic gene expression in A7r5 cells. The templates were reverse-transcription products of the A7r 5 cell line, whose RNA was extracted by the RNA extraction kit ofTIANGENand reverse transcribed by the MBIRevertAid ${ }^{\mathrm{TM}}$ First-Strand cDNA Synthesis Kit. The primers of the target genes were caspase-9 (forward: 5'-AAGACCATGGCTTTGAGGTG-3' and reverse: 5'-CAGGAACCGCTCTTCTTGTC-3') and caspase-3 (forward: 5'-TGTCGATGCAGCTAACCTCAGA-3' and reverse: 5'-CCACAG GTCCGTTCGTTCCAA-3'). The reaction was set up according to the TAKARA SYBR Premix Ex TaqII (Tli RNaseH Plus) KIT, and an ABI 7500 Fast Real-Time PCR System was used to perform PCR under the following conditions: initial denaturation at $95^{\circ} \mathrm{C}$ for $30 \mathrm{~s} ; 40$ cycles of $95^{\circ} \mathrm{C}$ for $3 \mathrm{~s}$ and $60^{\circ} \mathrm{C}$ for $30 \mathrm{~s}$; and a final melt curve. Amplified products were separated on $1 \%$ agarose gels and photographed with a Kodak Gel Logic 100 Imaging System. The densities of the bands were determined using the Gel-Pro Analyzer 4.0 software.

\section{Western blot analysis}

Treated cells were harvested and lysed in nondenaturing lysis buffer (Applygen Technologies, Beijing, China). Samples containing $30 \mu \mathrm{g}$ protein per lane were separated by $10 \%$ sodium dodecyl sulfate-polyacrylamide gel electrophoresis (SDS-PAGE) and transferred to polyvinylidene fluoride membranes. The membranes were blocked in 5\% skim milk-TBST (20 mM Tris-HCl, pH 7.5, $500 \mathrm{mM} \mathrm{NaCl}, 0.1 \%$ Tween 20 ) for $1 \mathrm{~h}$. Then, the respective primary antibodies for caspase- 3 and -9 were added in the same milk and incubated overnight at $4^{\circ} \mathrm{C}$, and the membrane was then incubated with horseradish peroxidase-conjugated secondary antibody in TBST for $2 \mathrm{~h}$ at room temperature. The blot was developed with LAS3000 chemiluminescence system (Fujifilm, Tokyo, Japan), and the densities of the bands were determined using the Gel-Pro Analyzer 4.0 software.

\section{Data acquisition and statistical analysis}

At least 3 independent experiments were performed per data point. The results are 
reported as means and standard deviations of these ratios. The differences of the means were analyzed by the Student $t$-test. P values that were $>0.05$ were not considered statistically significant.

\section{RESULTS}

\section{Cell viability}

To analyze whether the ultrasound treatment was toxic to the A7r5 cell line and to determine the optimal time course, the MTT assay was used to measure changes in cell viability. The results are reported as OD. Results showed that with longer exposure time (over $35 \mathrm{~s}$ ), the cell viability decreased sharply, as shown in Figure 2. Therefore, we chose less than $30 \mathrm{~s}$ as the optimal time point for apoptosis analysis by flow cytometry and $30 \mathrm{~s}$ for gene chip analysis to avoid too much cell death in the samples.

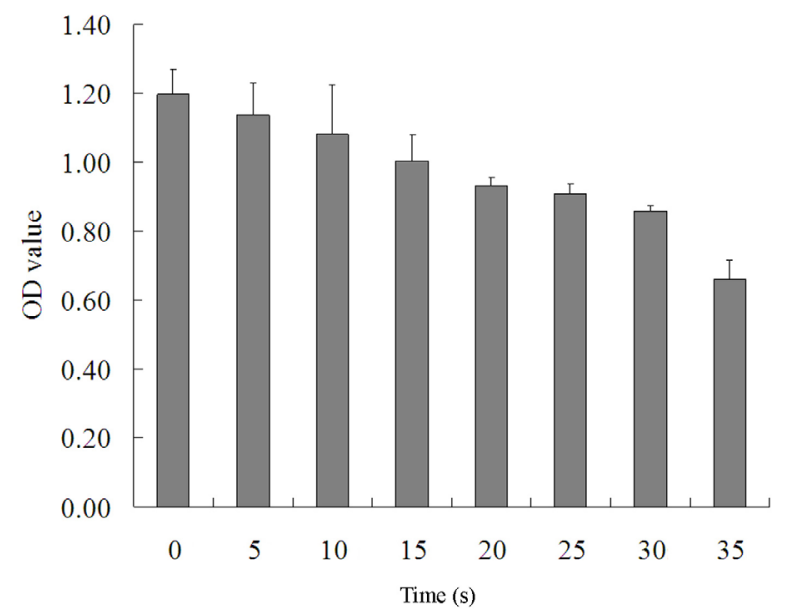

Figure 2. Viability of ultrasound treated A7r5 cells by MTT assay. The results represent one of three individual experiments. OD values of ultrasound-treated and -untreated A7r5 cells were measured by filter 492 .

\section{Apoptotic rates detected by flow cytometry}

The A7r5 cell apoptosis that was induced by low-frequency ultrasound was evaluated with flow cytometry. We found that the apoptosis rate increased with increasing ultrasound exposure time. Compared with the control group $(6.09 \pm 1.67)$, the apoptosis rate in treated groups $(10,20$, and $30 \mathrm{~s})$ was significantly higher $(11.96 \pm 1.52,15.74 \pm 2.16$, and $18.94 \pm$ 3.04; $\mathrm{P}<0.001$ ) (Figure 3). These results indicated that a significant amount of apoptosis could be induced by low-frequency ultrasound.

\section{Gene display analysis}

At the optimum exposure condition (30 s), gene chip analysis was performed on the 
ultrasound irradiation-treated and control group. There were significant changes in the gene expression of the caspase signaling pathways. The expression of caspase- 3 and caspase- 9 was upregulated over 1 time, as shown in Table 1. These results indicate that the intrinsic pathway may play a key role in apoptosis that is induced by low-frequency ultrasound. Further studies on the detailed mechanism should also be performed.
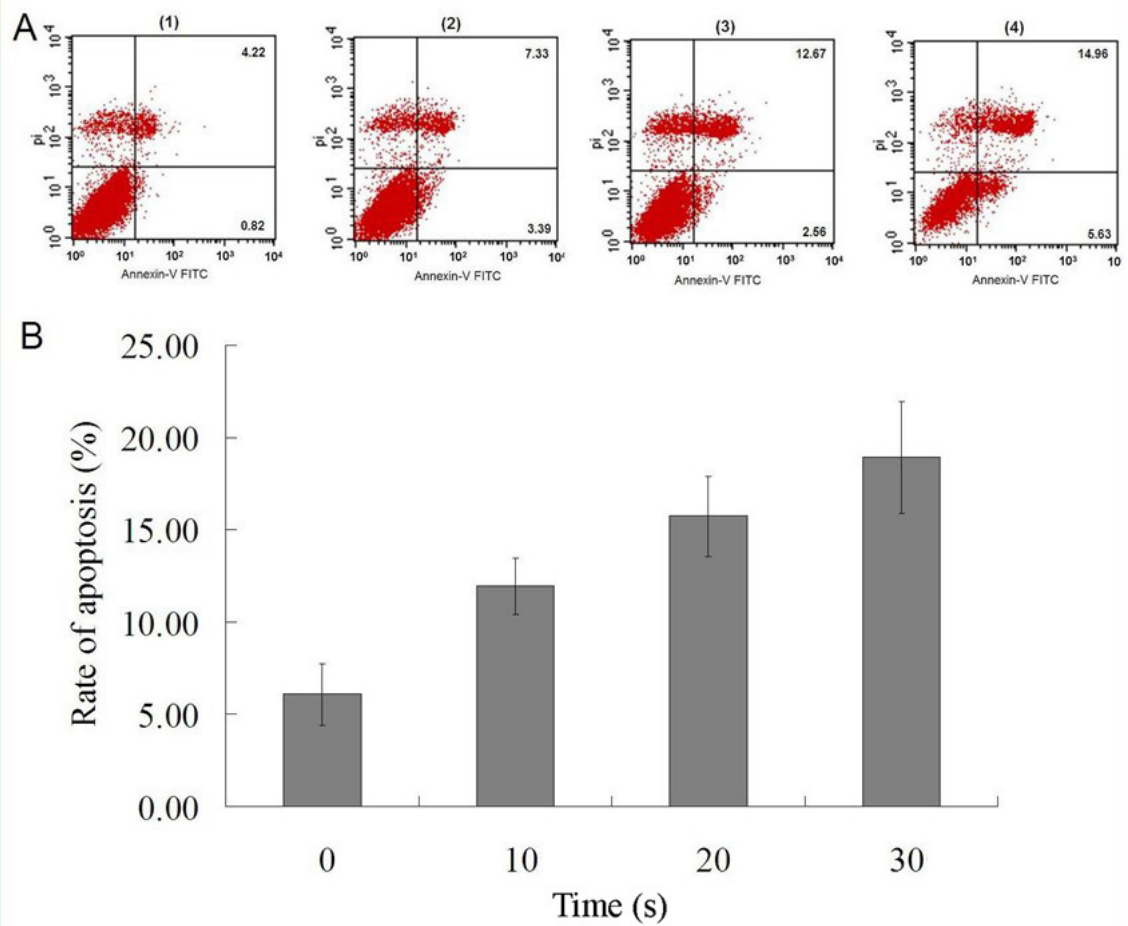

Figure 3. Detection of apoptotic cells by flow cytometry. A. Detection of apoptotic cells by flow cytometry at different exposure time to low-frequency ultrasound. A (1), (2), (3) and (4) represents exposure times 0, 10, 20, and $30 \mathrm{~s}$, respectively. B. Histograms show that there are significant higher rates of apoptosis in ultrasound irradiation groups compared with the control group ( $10 v s 0 \mathrm{~s}, \mathrm{P}<0.05 ; 20$ and $30 v s 0 \mathrm{~s}, \mathrm{P}<0.001, \mathrm{~N}=4)$.

Table 1. Differential expressed genes involved in caspase signaling pathways.

\begin{tabular}{lc}
\hline Name & Fold-change (overexpressed HSP27 group vs A7r5 group) \\
\hline CASP8AP2 & 1.45887 up \\
CASP3 & 1.01182 up \\
CASP6 & -1.31528 down \\
CASP8 & -1.13575 down \\
CASP10 & 1.24914 up \\
CASP14 & -1.00248 down \\
CASP1 & 1.43117 up \\
CASP5 & 1.33765 up \\
CASP4 & 1.04137 up \\
CASP12 & -1.15627 down \\
CASP7 & 1.01752 up \\
CASP9 & -1.03515 down \\
\hline
\end{tabular}




\section{Confirmation of RT-PCR and Western blot}

In order to confirm if the gene expression results were correct, RT-PCR and Western blot analysis of caspase- 9 and caspase-3 were performed (Figure 4). The results showed that caspase- 9 and caspase- 3 proteins were expressed higher in the ultrasound irradiation group than in the control group, as shown in Figure 4A and B, which is consistent with the results of the differential gene display. In the ultrasound irradiation group, the protein expression of caspase- 9 and caspase- 3 was increased by 50 and $57 \%$, respectively, compared with that in the control group. Additionally, the caspase- 3 mRNA level was increased by $37.5 \%$, but the caspase-9 mRNA level did not change, as shown in Figure 4C. The reason that no change was detected for the caspase- 9 mRNA level may be related to the late time course; caspase- 9 mRNA might be expressed in cultured cells in the very early stage after exposure to ultrasound. These results confirmed that the intrinsic apoptotic pathway played a very important role in cultured rat aortic smooth muscular cells (A7r5 cells) that was induced by low-frequency ultrasound.

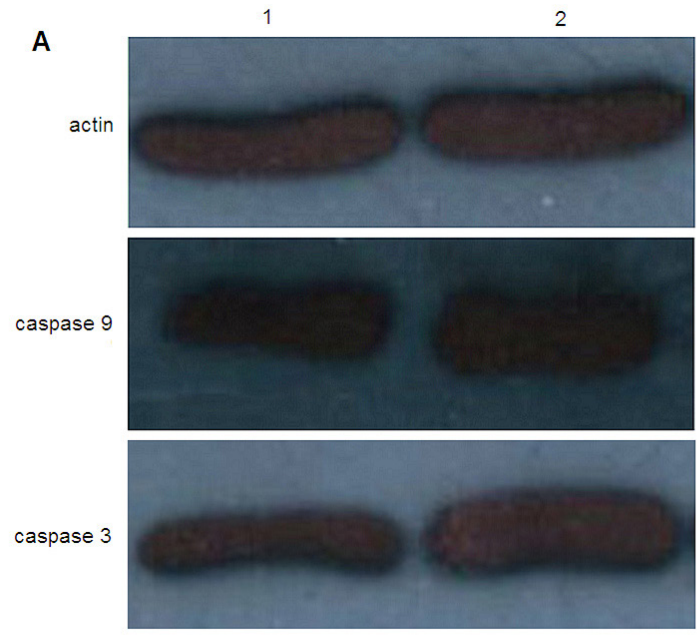

C

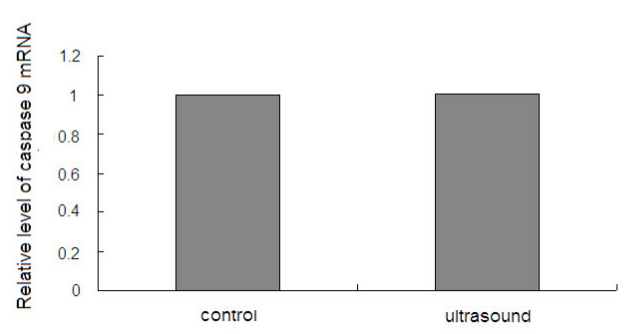

(1)

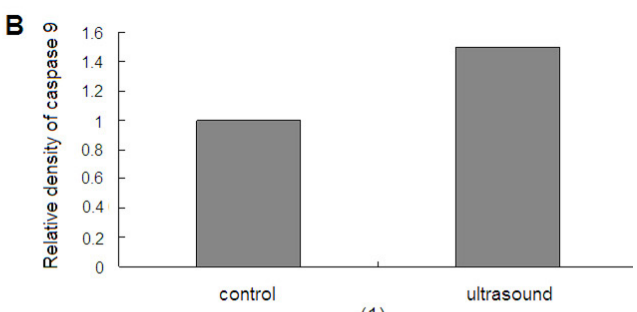

(1)

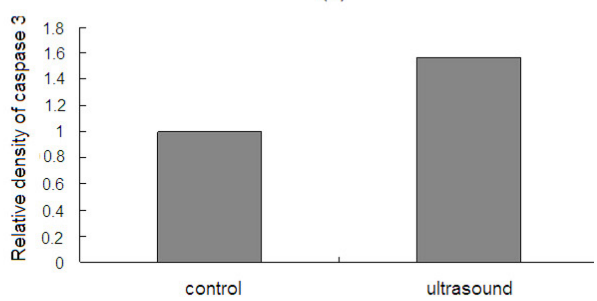

(2)

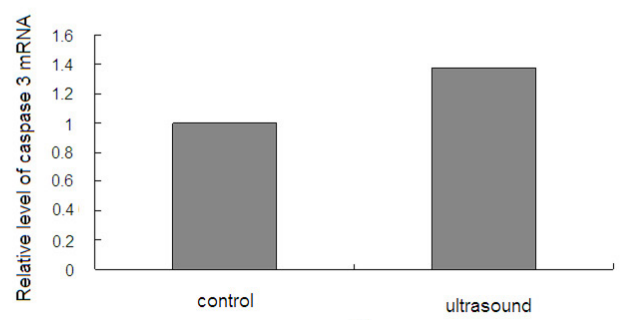

(2)

Figure 4. Western blot and RT-PCR analysis of caspase-9 and caspase-3. A. Immunoblotting assay for the inactive precursor of caspase- 9 and caspase-3. B. Histograms showing the densitometric analysis of caspase- 9 and caspase- 3 respectively; expression level of both caspase- 9 and caspase- 3 proteins was increased by 50 and $57 \%$, respectively. C. RT-PCR assay for the inactive precursor of caspase- 9 and caspase- 3 mRNA level respectively; caspase- 3 mRNA level in ultrasound-treated group was increased by $37.5 \%$, compared with the control group; but caspase- 9 mRNA level had no change; data represent one of three independent experiments. 


\section{DISCUSSION}

Apoptosis, or programmed cell death, is a normal physiologic process that contributes to the homeostasis of tissue and maintains the balance between cell proliferation and cell death. Apoptosis is always a special cellular response to stress stimuli, such as exposure to chemotherapeutic drugs, oxidative stress, free radicals, X-rays, ultraviolet radiation, and physical stress including ultrasonic irradiation (Feng et al., 2008; Vlad et al., 2011). Apoptosis occurs through 2 main pathways: the extrinsic (death ligand) and intrinsic (mitochondrial) pathway (Salvesen, 2002; Harrington et al., 2008; Ghavami et al., 2009). This extrinsic activation then triggers the hallmark caspase cascade that is characteristic of the apoptotic pathway, in which caspase-3 plays a dominant role (Perry et al., 1997; Stennicke et al., 2000). In intrinsic activation, cytochrome $\mathrm{c}$ from the mitochondria works in combination with caspase-9, apoptosis-activating factor 1, and ATP to process caspase-3 (Katunuma et al., 2001; Li et al., 2004), which subsequently activates the rest of the caspase cascade and leads to apoptosis.

A new non-invasive method to detect DNA damage using mid- to high-frequency ultrasound $(10-60 \mathrm{MHz})$ has been developed for future investigations regarding the use of ultrasound in preclinical and clinical settings to non-invasively monitor tumor responses to specific interventions that induce cell death (Vlad et al., 2011). Although reports showed that tumor cell death could be induced by low-frequency, low-intensity ultrasound and that the apoptotic pathways were caspase-3-dependent with or without the involvement of bax (a pro-apoptotic protein) and bcl-2 (an anti-apoptotic protein) (Bai et al., 2012; Zhang et al., 2012), we did not know if VSMCs respond like tumor cells. Besides, there are few reports about the effect of low-frequency ultrasound irradiation on apoptosis of VSMCs. Thus, we were prompted to investigate the effect and possible mechanism of VSMCs that were exposed to low-frequency ultrasound.

The exposure time is an important index in this study. The MTT results revealed that the cell viability decreased sharply with longer exposure time (over $35 \mathrm{~s}$ ) (Figure 2). Therefore, we chose less than $30 \mathrm{~s}$ as the optimal time point for apoptosis analysis by flow cytometry and $30 \mathrm{~s}$ for gene chip analysis to avoid too much cell death in the samples.

The apoptosis of this cell line was evaluated at the optimal time point in our lab for cell death $(<30 \mathrm{~s})$ because exposure to ultrasound alone resulted in minimal cell death (Figure 2 ). We found that apoptosis could be induced in $\mathrm{A} 7 \mathrm{r} 5$ cells by continuous $45-\mathrm{kHz} 1.0-\mathrm{W} / \mathrm{cm}^{2}$ ultrasound treatment.

Our results indicated that when treated with low-frequency ultrasound, the protein expression of caspase- 9 and caspase- 3 was increased by 50 and $57 \%$, respectively. Additionally, the caspase- 3 mRNA level was increased by $37.5 \%$, but the caspase- 9 mRNA level did not change. These results suggested that the intrinsic apoptotic pathway was induced in VSMCs that were exposed to ultrasound. The proliferation and apoptosis of VSMCs play important roles in the pathologic restenosis of blood vessels after percutaneous transluminal angioplasty and stenting (Reimers et al., 1997). Therefore, ultrasound treatment may potentially be considered as a new therapeutic tool for intimal hyperplasia. However, further investigations are needed to clear the following questions:

1) How does ultrasound induce the intrinsic apoptotic process?

2) Does the extrinsic (death ligand) pathway play any role in the apoptotic process?

3 ) Is a new pathway involved in the apoptotic process that is induced by low-frequency ultrasound? 
Taken together, our results showed the remarkable activation of caspase-9 and caspase-3 in aortic smooth muscle cells, indicating that the intrinsic pathway (caspase-9- and caspase-3-dependent) plays a major role in the A7r5 cell apoptotic process that is induced by continuous $45-\mathrm{kHz} 1.0-\mathrm{W} / \mathrm{cm}^{2}$ ultrasound.

\section{ACKNOWLEDGMENTS}

Research supported by the Shanghai Pujiang Project of China (Grant \#09PJ1408800), the Academic Leaders Training Program of Pudong Health Bureau of Shanghai (Grant \#PWRd2013-02), and the National Natural Science Foundation of China (Grant \#81271597).

\section{REFERENCES}

Ahmadi F, McLoughlin IV, Chauhan S and ter-Haar G (2012). Bio-effects and safety of low-intensity, low-frequency ultrasonic exposure. Prog. Biophys. Mol. Biol. 108: 119-138.

Bai WK, Wu ZH, Shen E, Zhang JZ, et al. (2012). The improvement of liposome-mediated transfection of pEGFP DNA into human prostate cancer cells by combining low-frequency and low-energy ultrasound with microbubbles. Oncol. Rep. 27: 475-480.

Beamish JA, He P, Kottke-Marchant K and Marchant RE (2010). Molecular regulation of contractile smooth muscle cell phenotype: implications for vascular tissue engineering. Tissue Eng. Part B Rev. 16: 467-491.

Chida S, Okada K, Suzuki N, Komori C, et al. (2009). Infiltration by macrophages and lymphocytes in transplantable mouse sarcoma after irradiation with high-intensity focused ultrasound. Anticancer Res. 29: 3877-3882.

Fang HY, Tsai KC, Cheng WH, Shieh MJ, et al. (2007). The effects of power on-off durations of pulsed ultrasound on the destruction of cancer cells. Int. J. Hyperthermia 23: 371-380.

Feng Y, Tian ZM, Wan MX and Zheng ZB (2008). Low intensity ultrasound-induced apoptosis in human gastric carcinoma cells. World J. Gastroenterol. 14: 4873-4879.

Ghavami S, Hashemi M, Ande SR, Yeganeh B, et al. (2009). Apoptosis and cancer: mutations within caspase genes. $J$. Med. Genet. 46: 497-510.

Harrington HA, Ho KL, Ghosh S and Tung KC (2008). Construction and analysis of a modular model of caspase activation in apoptosis. Theor. Biol. Med. Model. 5: 26.

Hayashi K and Naiki T (2009). Adaptation and remodeling of vascular wall; biomechanical response to hypertension. $J$. Mech. Behav. Biomed. Mater. 2: 3-19.

Hundt W, Yuh EL, Bednarski MD and Guccione S (2007). Gene expression profiles, histologic analysis, and imaging of squamous cell carcinoma model treated with focused ultrasound beams. AJR Am. J. Roentgenol. 189: 726-736.

Jiang Z, Wu W and Qian ML (2012). Cellular damage and apoptosis along with changes in NF-kappa B expression were induced with contrast agent enhanced ultrasound in gastric cancer cells and hepatoma cells. Cancer Cell Int. 12: 8.

Katunuma N, Matsui A, Le QT, Utsumi K, et al. (2001). Novel procaspase-3 activating cascade mediated by lysoapoptases and its biological significances in apoptosis. Adv. Enzyme Regul. 41: 237-250.

Lejbkowicz F and Salzberg S (1997). Distinct sensitivity of normal and malignant cells to ultrasound in vitro. Environ. Health Perspect. 105 (Suppl 6): 1575-1578.

Li P, Nijhawan D and Wang X (2004). Mitochondrial activation of apoptosis. Cell 116: S57-S59.

Man J, Shelton RM, Cooper PR and Scheven BA (2012). Low-intensity low-frequency ultrasound promotes proliferation and differentiation of odontoblast-like cells. J. Endod. 38: 608-613.

Meng QQ, Chen BA, Wu W, Shao ZY, et al. (2008). Antitumor effects of low-frequency ultrasound combined with adriamycin on human leukemia multidrug resistance cell line K562/A02. Ai Zheng 27: 1182-1185.

Owens GK, Kumar MS and Wamhoff BR (2004). Molecular regulation of vascular smooth muscle cell differentiation in development and disease. Physiol. Rev. 84: 767-801.

Paliwal S, Sundaram J and Mitragotri S (2005). Induction of cancer-specific cytotoxicity towards human prostate and skin cells using quercetin and ultrasound. Br. J. Cancer 92: 499-502.

Perry DK, Smyth MJ, Stennicke HR, Salvesen GS, et al. (1997). Zinc is a potent inhibitor of the apoptotic protease, caspase-3. A novel target for zinc in the inhibition of apoptosis. J. Biol. Chem. 272: 18530-18533.

Reimers B, Moussa I, Akiyama T, Tucci G, et al. (1997). Long-term clinical follow-up after successful repeat percutaneous intervention for stent restenosis. J. Am. Coll. Cardiol. 30: 186-192. 
Rokhina EV, Lens P and Virkutyte J (2009). Low-frequency ultrasound in biotechnology: state of the art. Trends Biotechnol. 27: 298-306.

Salvesen GS (2002). Caspases: opening the boxes and interpreting the arrows. Cell Death Differ. 9: 3-5.

Stennicke HR, Renatus M, Meldal M and Salvesen GS (2000). Internally quenched fluorescent peptide substrates disclose the subsite preferences of human caspases 1, 3,6, 7 and 8. Biochem. J. 350: 563-568.

Tsuang YH, Liao LW, Chao YH, Sun JS, et al. (2011). Effects of low intensity pulsed ultrasound on rat Schwann cells metabolism. Artif. Organs 35: 373-383.

Tusher VG, Tibshirani R and Chu G (2001). Significance analysis of microarrays applied to transcriptional responses to ionizing radiation. Proc. Natl. Acad. Sci. U. S. A. 98: 5116-5121.

Vlad RM, Kolios MC and Czarnota GJ (2011). Ultrasound imaging of apoptosis: spectroscopic detection of DNA-damage effects at high and low frequencies. Methods Mol. Biol. 682: 165-187.

Xia CY, Liu YH, Wang P and Xue YX (2012). Low-frequency ultrasound irradiation increases blood-tumor barrier permeability by transcellular pathway in a rat glioma model. J. Mol. Neurosci. 48: 281-290.

Zhang Z, Xue Y, Liu Y and Shang X (2010). Additive effect of low-frequency ultrasound and endothelial monocyteactivating polypeptide II on blood-tumor barrier in rats with brain glioma. Neurosci. Lett. 481: 21-25.

Zhang Z, Chen J, Chen L, Yang X, et al. (2012). Low frequency and intensity ultrasound induces apoptosis of brain glioma in rats mediated by caspase-3, Bcl-2, and surviving. Brain Res. 1473: 25-34. 